\title{
Rutin prevents retinal ganglion cell death and exerts protective effects by regulating transforming growth

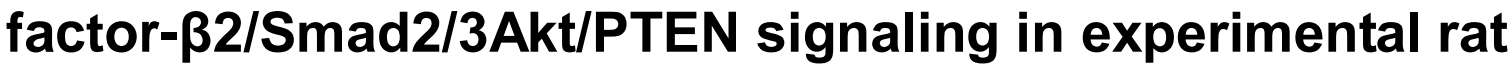 glaucoma
}

\author{
Ying Li ${ }^{1}$, Leilei Qin ${ }^{1}$, Liang Ying ${ }^{2}$, Hanguang Dong ${ }^{3}$, Dabo Wang ${ }^{4 *}$ \\ ${ }^{1}$ Ophthalmology Center, The Affiliated Qingdao Municipal Hospital of Qingdao University, Qingdao, Shandong Province \\ 266000, China, ${ }^{2}$ Department of Special Examination, Qingdao Huaxia Eye Hospital, Qingdao, Shandong Province 266000, \\ China, ${ }^{3}$ Department of General Surgery, Qilu Hospital of Shandong University (Qingdao), Qingdao, Shandong Province 266000, \\ China, ${ }^{4}$ Department of Ophthalmology, The Affiliated Hospital of Qingdao University, Qingdao, Shandong Province 266000, \\ China
}

*For correspondence: Email: DebroahKedleth@yahoo.com; Tel/Fax: 0086-53282911201

\begin{abstract}
Purpose: To investigate the protective effect of rutin against glaucoma in a rat model, and the mechanisms involved.

Methods: Sprague-Dawley rats were injected hypertonic saline in the limbal vein for elevation of intraocular pressure (IOP). Rats in the treatment group were administered rutin at doses of 12.5, 25 or 50 $\mathrm{mg} / \mathrm{kg}$ orally and daily for 21 days.

Results: Rutin markedly $(p<0.05)$ reduced IOP and prevented loss of retinal ganglion cells (RGCs). The expression of apoptotic pathway proteins, i.e., Bcl-xL, Bcl-2, Bad and Bax were significantly ( $p<$ $0.05)$ regulated by rutin. Moreover, rutin caused a substantial decrease in TGF- $\beta 2$ expression, and also down-regulated $p$-Smad2 and $p$-Smad3 dose-dependently $(p<0.05)$. Raised levels of collagen I, fibronectin and elastin were effectively down-regulated. Rutin substantially up-regulated the Akt pathway involved in cell survival, and markedly improved the survival of RGCs subjected to hypoxia in vitro ( $p<$ 0.05).

Conclusion: These results reveal that rutin exerts protective effect against glaucoma in a rat model via

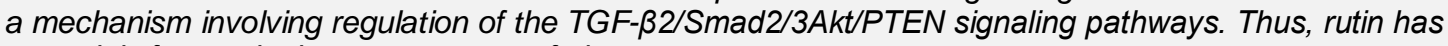
potentials for use in the management of glaucoma.
\end{abstract}

Keywords: Apoptosis, Glaucoma, Rutin, Retinal ganglion cell, Smad signaling, Transforming growth factor $\beta$

\footnotetext{
This is an Open Access article that uses a fund-ing model which does not charge readers or their institutions for access and distributed under the terms of the Creative Commons Attribution License (http://creativecommons.org/licenses/by/4.0) and the Budapest Open Access Initiative (http://www.budapestopenaccessinitiative.org/read), which permit unrestricted use, distribution, and reproduction in any medium, provided the original work is properly credited.

Tropical Journal of Pharmaceutical Research is indexed by Science Citation Index (SciSearch), Scopus, International Pharmaceutical Abstract, Chemical Abstracts, Embase, Index Copernicus, EBSCO, African Index Medicus, JournalSeek, Journal Citation Reports/Science Edition, Directory of Open Access Journals (DOAJ), African Journal Online, Bioline International, Open-J-Gate and Pharmacy Abstracts
}

\section{INTRODUCTION}

Glaucoma is a complex progressive optic neuropathic condition characterized by loss of retinal ganglion cells (RGC), leading to visual impairment [1]. The principal risk factor implicated in glaucoma pathogenesis is abnormal elevation of intra-ocular pressure (IOP) [2]. The 
RGCs are extremely susceptible to stress from aberrantly elevated IOP; increased resistance to aqueous humor $(\mathrm{AH})$ outflow is associated with elevated IOP [3].

The trabecular meshwork (TM) is an optic tissue composed of layers of trabecular beams surrounded by elastic fibers, fibronectin and laminin. The trabecular cells secrete extracellular matrix (ECM) components, and are associated with ECM signals [4]. The trabecular meshwork (TM) exhibits several morphological and biochemical changes including decreased cellularity, ECM accumulation and changes in actin cytoskeleton in glaucomatous conditions, all of which contribute to increased resistance to $\mathrm{AH}$ outflow, thereby leading to high IOP [5].

Transforming growth factor- $\beta$ (TGF- $\beta$ ) is one of the major cytokines with wide range of functions. It is crucial for maintenance of optic tissue homeostasis and neovascularization in the optic tissues [6]. Isoforms of TGF- $\beta$, on binding to their receptors, initiate intracellular signals via Smad proteins which have numerous subtypes [7]. The TGF- $\beta$ receptors phosphorylate Smad-2 and Smad-3. When phosphorylated, Smad-2 and Smad-3 bind to Smad-4, and the Smad-2-Smad3-Smad-4 complex gets translocated from cytosol to nucleus, and activate transcription of target genes leading to ECM production. It is known that TGF- $\beta 2$ induces expressions of ECM proteins such as collagen, elastin, fibronectin and proteoglycans, and also induces inhibitors of proteolytic degradation of ECM [8].

The PI3K/Akt pathway is a major signaling pathway associated with cell survival [9]. It has been reported that the AKT pathway promoted RGC survival in experimental animal models of glaucoma [10]. Phosphatase and tensin homolog (PTEN), the major negative regulator of the pathway, acts as a cofactor for Smad2/3 phosphatase and regulates TGF- $\beta$ signaling and ECM deposition. Phosphorylation of PTEN at Thr382, Thr383 and Ser380 reduces its activity and aids in activation of AKT signaling [11]. Understanding of cell signaling mechanisms by which TGF- $\beta$ induces excess ECM deposition gives an insight into the pathogenesis of glaucoma. Thus, compounds that target key pathways in glaucoma would be immensely valuable in its therapy.

Evidence suggests that sufficient consumption of fruits and vegetables can lower the risk of cataracts in humans [12]. Flavonoids are a large family of phytochemicals that are widely distributed in fruits and vegetables. Rutin $(3,3$, 4', 5, 7-pentahydroxyflavone-3-rhamnoglucoside) is a flavonoid which is abundantly present in citrus fruits such as lime, oranges, lemons and grapefruits [13]. Rutin possess antioxidant activities [14], as well as neuroprotective [15], anti-diabetic [16], and anti-cancer effects [17]. Considering the wide pharmacological properties of rutin, the present investigation was carried out to study its effect on RGC survival and TGF$\beta 2 / A K T / P T E N / S m a d$ pathways in experimental glaucoma.

\section{EXPERIMENTAL}

\section{Chemicals and antibodies}

Antibodies against transforming growth factors $\beta$ (TGF- $\beta$ ), TGF- $\beta 2$, PTEN, p-PTEN, Akt, p-Akt, GSK-3 $\beta, \quad p-G S K-3 \beta$, and collagen I were procured from Cell Signaling Technology (Danvers, MA, USA), while antibodies against cleaved caspase-3, Bcl-2, Bcl-xL, Bad, Smad-2, Smad-3, phospho-Smad-2, phospho-Smad-3, fibronectin, elastin, $\beta$-actin and horseradish peroxidase-labelled $\lg$ secondary antibodies used for expression analysis were purchased from Santa Cruz Biotechnology (Texas, USA). Dulbecco's modified Eagle's medium (DMEM)-F12 was product of Thermo-Fischer Scientific. Rutin, buffers used in Western blotting analysis and chemicals used in the study were obtained from Sigma-Aldrich (St. Louis, MO, USA).

\section{Experimental animals}

Male Sprague Dawley rats weighing 180 - $200 \mathrm{~g}$ $(n=60)$ from Qingdao University animal study facility were used. The study designed and the protocols involved in the study were approved by the Institutional ethical committee of the Qingdao University (no. XY246123). The procedures and animal handling were conducted in accordance with the National Guidelines of Animal Care Committee in line with the International guidelines for study of laboratory animals [18].

The rats were housed in sterile cages ( 3 animals per cage), and were maintained under 12-h day/12-h night cycle in controlled laboratory conditions at a relative humidity of $55-60 \%$ and temperature of $22-23{ }^{\circ} \mathrm{C}$. The rats were acclimatized to the animal house conditions for 5 days before the initiation of the study.

\section{Study design}

The rats were randomly divided to 6 treatment groups ( $n=12 /$ group). For experimental induction of glaucoma, rats were anesthetized (ketamine $100 \mathrm{mg} / \mathrm{mL}$ ) and xylazine $(20 \mathrm{mg} / \mathrm{mL}$ ) and a drop of proparacaine hydrochloride $(0.5 \%)$ 
was applied onto each eye. Intra ocular pressure (IOP) was measured instantly following anesthesia.

Hypertonic saline solution was injected into the eyes of the animals to induce experimental glaucoma. A stable baseline IOP was documented prior injection of saline. Approximately $50 \mu \mathrm{L}$ of $2 \mathrm{M}$ hypertonic saline was injected into the limbal venous system as previously described [19]. Separate groups of rats (group III - V) received rutin at 12.5, 25 or 50 $\mathrm{mg} / \mathrm{kg}$ dose orally via gavage per day starting 24 $\mathrm{h}$ after glaucoma induction for 3 weeks. The glaucoma group (Group II) received equal volume of saline following glaucoma induction. Control group (Group I): the group received no medication, although an equal volume of saline solution was injected into the right eyes for hypertonic saline. Group VI: animals were administered with rutin at $50 \mathrm{mg} / \mathrm{kg}$ and were not injected with hypertonic saline.

\section{IOP measurement}

IOP was measured under anesthesia as mentioned above. A calibrated Tonolab tonometer was used for measurement (Colonial Medical Supply Company, Franconia, NH, USA). IOP was measured every week for consecutive 6 weeks as suggested by Moore et al [20].

\section{Retrograde labelling of RGCs and counting}

The rats were deeply anesthetized as described previously and the superior colliculus on each side was injected with $2 \mathrm{~mL}$ Fluoro-Gold (FG, 5 $\%$ in PBS) as previously reported. Seven days after $F G$ injection, the animals were euthanatized and the eyeballs were enucleated and fixed for 2 $\mathrm{h}$ at room temperature in paraformaldehyde (4 $\%)$. The retinas were cautiously dissected and observed. RGC were counted in the inner and peripheral retina at 1.5 to $2.0 \mathrm{~mm}$ and 3.5 to 4.0 $\mathrm{mm}$ from the optic disc. The RGC were quantified at $200 \times$ under laser scanning confocal microscope (TCSSP8, Hamburg, Germany). Average counts in eight microscopic fields of identical size were calculated and the density is presented as number of cells $/ \mathrm{mm}^{2}$.

\section{Immunohistochemistry}

The eye sections $(10 \mu \mathrm{m})$ were incubated in 0.1 $\%$ Triton X-100 and bovine serum albumin (BSA; $3 \% \mathrm{w} / \mathrm{v}$ ) at room temperature for $30 \mathrm{~min}$. The eye sections were incubated with primary antibodies (anti-cleaved caspase- 3 and antisurvivin) at $4^{\circ} \mathrm{C}$ overnight followed by incubation with fluorescein-conjugated secondary antibody
(Molecular Probes, Waltham, MA, USA) and Hoechst staining [21]. The sections were then visualized via confocal microscopy (Leica SP8, Hamburg, Germany).

\section{Western blotting}

The retinal or the RGC cells were subjected to cell lysis and total protein were extracted using cell lysis buffer with protease inhibitor cocktail (Sigma-Aldrich, St. Louis, MO, USA). Total protein was quantified using BCA protein assay kit (Thermo Fisher Scientific, Rockford, IL, USA). Equivalent volumes of sample proteins $(60 \mu \mathrm{g})$ from different treatments were run on SDSPAGE (10-12 \%) and separated electrophoretically. The protein bands were blotted onto PVDF membranes (Invitrogen). The blotted membranes were blocked using TBST buffer (20 mM Tris -pH7.6; $137 \mathrm{mM} \mathrm{NaCl} ; 0.1 \%$ Tween 20) containing $5 \%$ non-fat milk for 60 min at $37{ }^{\circ} \mathrm{C}$. Membranes were then incubated overnight at $4{ }^{\circ} \mathrm{C}$ with specific primary antibodies (1:1000 dilution). Later, the membranes were then washed with TBST and incubated at $37^{\circ} \mathrm{C}$ for 60 min with HRP-labelled secondary antibody (1: 2000 dilution). The positive bands were detected by enhanced chemiluminescence method (Millipore, USA) and analysed by ChemiDoc XRS imaging system (Bio-Rad, USA). The band intensities of the test proteins were normalised with expressions of $\beta$-actin that was used as internal control.

\section{Real-time (RT) PCR analysis}

Total RNA from the retinal tissues were isolated using RN easy kit (Qiagen Inc. Valencia, CA) according to the manufacturer's protocol and total RNA content was estimated using RiboGreen fluorescent dye (Molecular Probes Inc. Eugene, OR). First strand of cDNA was synthesized using CDNA reverse transcription kit (Applied Biosystems, CA, USA). PCR was carried out by means of 7300 Real-Time PCR System (Applied Biosystems) with SYBR green fluorescence. The following primers were used for amplification- Smad2-forward, 5'ATGTCGTCCATCTTGCCATTC-3', reverse, 5'AACCGTCCTGTTTTCTTTAGCTT-3'; Smad3forward:5'-CATTACCATCCCCAGGTCAC-3',

reverse,5' CGTAATTCATGGTGGCTGTG-3'; GAPDH- forward: 5'-CACCACCATGGAGAAGG C-3', reverse: 5'-CCATCCACAGTCTTC TGA-3'. The final PCR products were exposed to agarose gel electrophoresis (2\%). The bands were stained with ethidium bromide $(0.05 \%)$ and the intensities were analysed by Bio-Gel imagery apparatus (Bio-Rad, USA). 


\section{RGC isolation and cell culture}

RGCs were isolated from 3-day old SpragueDawley pups and cultured. The purity was also checked as described by Gao et al [22]. The cells were cultured in Dulbecco's modified Eagle's medium (DMEM)-F-12 (Thermo-Fischer Scientific), supplemented with $4 \mathrm{mM}$ glutamine, $10 \%$ fetal bovine serum (FBS), $100 \mathrm{U} / \mathrm{mL}$ penicillin, and $100 \mu \mathrm{g} / \mathrm{mL}$ streptomycin. The cells were cultured at $37^{\circ} \mathrm{C}$ in the presence of $5 \%$ $\mathrm{CO}_{2}$. Hypoxic conditions were induced by exposing RGCs to $200 \mu \mathrm{M}$ cobalt chloride $\left(\mathrm{CoCl}_{2}\right)$ for $48 \mathrm{~h}$ [23]. Fresh medium was replaced and varying concentrations of rutin (10, $20,40,80,100 \mu \mathrm{M}$ ) was added and incubated for $48 \mathrm{~h}$.

\section{Determination of RGC viability}

Following exposure to $\mathrm{CoCl}_{2}$ and rutin, cell viability was analysed using Vybrant ${ }^{\circledR}$ MTT Cell Proliferation Assay Kit (Thermo Fischer Scientific, USA) and by TUNEL assay using TUNEL assay kit - BrdU-Red (Abcam, USA) according to manufacturer's instructions.

\section{Statistical analysis}

The data were subjected to statistical analysis using version 22.0 SPSS software (SPSS Inc, Chicago, USA). Multiple group comparisons were done using ANOVA (one-way analysis of variance) followed by Duncan's Multiple Range Test (DMRT). Values of $p<0.05$ were considered statistically significant.

\section{RESULTS}

\section{Rutin effectively reduced IOP in glaucoma- induced rats}

There was a significant $(p<0.05)$ increase in IOP $24 \mathrm{~h}$ after glaucoma induction by injection of hypertonic saline (Figure 1). The IOP remained steadily high in the animals treated with saline alone for over 4 weeks, following which a nonsignificant decrease was noticed. Rats treated with rutin $(12.5,25$ or $50 \mathrm{mg})$ exhibited significantly $(p<0.05)$ lower IOP than rats in group II throughout the period of study. The rats treated with rutin alone presented IOP close to normal levels throughout observation period, suggesting that rutin administration did not affect IOP. In glaucoma control rats, IOP increased from $15 \mathrm{mmHg}$ in the $1^{\text {st }}$ week to $34.5 \mathrm{mmHg}$ in the $3^{\text {th }}$ week, and to $34.0 \mathrm{mmHg}$ at weeks 4 and 5. However, at week 6 , the IOP slightly dropped to $33 \mathrm{mmHg}$, while it dropped from 35.5 to 15.0 $\mathrm{mmHg}$ on treatment with $50 \mathrm{mg}$ rutin at week 5 .
At week 6 , the IOP levels were $10 \mathrm{mmHg}$ in rats treated with $50 \mathrm{mg}$ rutin. These observations indicate the potency of rutin in reducing IOP, which is of significant clinical value in treatment of glaucoma.

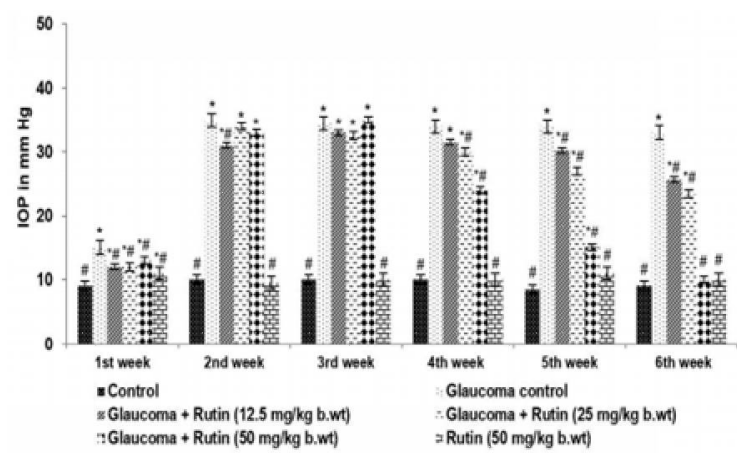

Figure 1: Effect of rutin on IOP levels following glaucoma induction

Data are presented as mean $\pm \operatorname{SD}(n=6) .{ }^{*} p<$ 0.05 , compared with control; \#p $<0.05$, compared with glaucoma control; a - e represent mean values that differ from each other at $p<$ 0.05 as determined using one-way ANOVA and DMRT analyses.

\section{Rutin promoted RGC survival}

The effect of rutin on RGC survival under glaucomatous conditions was assessed by retrograde FG labelling. Following induction of glaucoma, a significant reduction in RGC density was observed (Figure 2). Rutin treatment significantly $(p<0.05)$ increased RGC survival as reflected by viable cell density. Rutin at a dose of $50 \mathrm{mg}$ exerted maximal protective effects as shown by significant increase in RGC from 1412.1 cells $/ \mathrm{mm}^{2}$ to 2180 cells $/ \mathrm{mm}^{2}$. Furthermore, there was no significant difference in density of RGCs in rats treated with rutin alone, when compared with normal control rats.

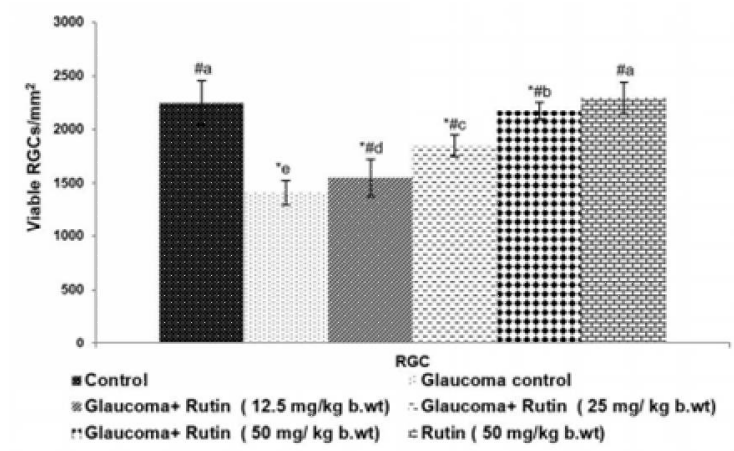

Figure 2: Effect of rutin on the viability of retinal ganglion cells

Data are presented as mean $\pm \mathrm{SD}(\mathrm{n}=6) .{ }^{*} p<$ 0.05 , compared with control; $\# p<0.05$, 
compared with glaucoma control; a - e represent mean values that differ from each other at $p<$ 0.05 as determined using one-way ANOVA and DMRT.

In vitro studies also revealed improved proliferation of RG cells exposed to $\mathrm{CoCl}_{2}$ (Figure 3) on incubation with rutin $(10-100 \mu \mathrm{M})$. The RGC cell viability increased to $98.1 \%$ from 49.2 $\%$ on incubation with $100 \mu \mathrm{M}$ rutin. These results indicate the protective effects of rutin on RGCs under stress.

A

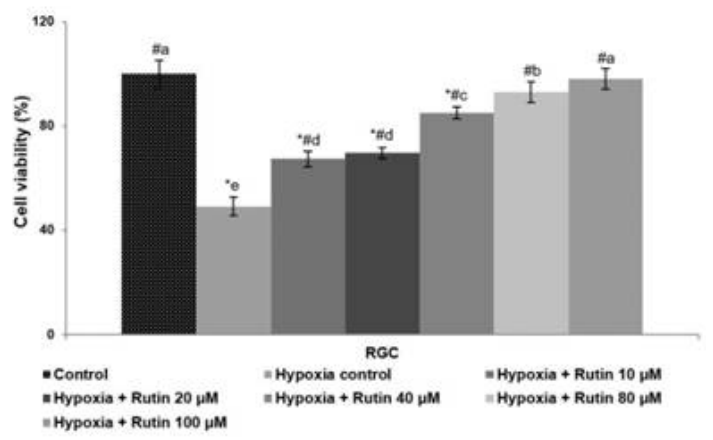

B

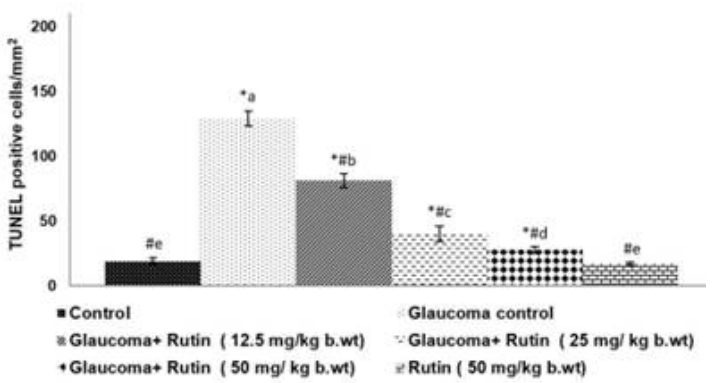

Figure 3: Effect of rutin on cell viability of retinal ganglion cells exposed to hypoxic conditions. (A) Rutin improved viability of RGC cells under hypoxic conditions in vitro. (B) Rutin reduced RGC apoptosis in glaucomatous rats, as determined by TUNEL assay. Data are presented as mean $\pm S D, n=6 .{ }^{*} p<0.05$, compared to normal control; $\# p<0.05$, compared to hypoxic control; $\# p<0.05$, compared to glaucoma control; a-e represents mean values that differ from each other as derived using one-way ANOVA and DMRT

\section{Rutin down regulated cleaved caspase- 3 and expressions of pro-apoptotic proteins}

The effect of rutin on extent of activation of caspase-3 under glaucomatous conditions was determined by assessing the expression levels of cleaved caspase-3 and apoptotic pathway proteins. Following glaucoma induction, marked $(p<0.05)$ increase in cleaved caspase-3 expression and considerable decrease in survivin levels were observed (Figure 4). These observations suggest that the saline injection raised the degree of apoptosis. Furthermore, there were significantly increased expressions of $\mathrm{Bax}$ and $\mathrm{Bad}$, and marked reductions in the expression levels of $\mathrm{Bcl}-2$ and $\mathrm{Bcl}-\mathrm{xL}$ in the glaucomatous rats (Figure 4). However, the administration of rutin at all the three tested doses resulted in remarkably downregulated expressions of Bax and Bad, while Bcl-xL and Bcl-2 were significantly upregulated $(p<0.05)$. Although 12.5 and $50 \mathrm{mg}$ modulated protein expression, the higher dose of $50 \mathrm{mg}$ brought more pronounced effects, which suggests that the effect of rutin was dose-dependent. These results indicate that rutin regulates the expressions of apoptotic pathway proteins.
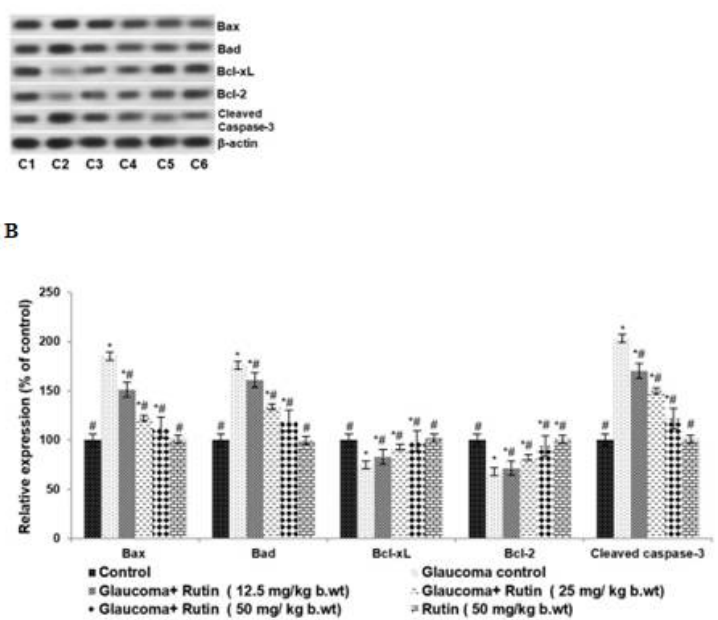

Figure 4: Effect of rutin on the expressions of apoptotic pathway proteins. (A) Representative immunoblot of proteins, and (B) relative expressions of proteins, with control expressions set at $100 \%$. Data are presented as mean $\pm \mathrm{SD}(\mathrm{n}=6)$. ${ }^{*} p<0.05$, compared with normal control; $\# p<0.05$, compared with glaucoma control. $\mathrm{Cl}=$ Control; $\mathrm{C} 2$ = glaucoma control; C3 = glaucoma+ rutin $(12.5 \mathrm{mg} / \mathrm{kg}) ; \mathrm{C} 4=$ glaucoma+ rutin $(25 \mathrm{mg} / \mathrm{kg}) ; \mathrm{C} 5=$ glaucoma + rutin $(50 \mathrm{mg} / \mathrm{kg}) ; \mathrm{C} 6$ = rutin $(50 \mathrm{mg} / \mathrm{kg})$

\section{Rutin up-regulated TGF- $\beta 2$ and Smad expressions}

The expression of TGF- $\beta 2$ was markedly raised in the glaucoma rats, when compared to normal control (Figure 5). Enhanced levels of phosphorylated forms of Smad-2 and 3 were observed following saline injection, an indication of activation of Smad signaling. Moreover, there were significant increases in the mRNA and protein expressions of total Smad-2 and Smad-3 levels. Interestingly, rutin caused a substantial decrease in TGF- $\beta 2$ expression, and also downregulated $p$-Smad2 and $p$-Smad3 dose- 
dependently, while the expression of total Smad2 and 3 were brought back to near normal control levels. Rutin at $50 \mathrm{mg}$ suppressed TGF- $\beta 2$ more effectively than at the lower doses of 12.5 and 25 mg.
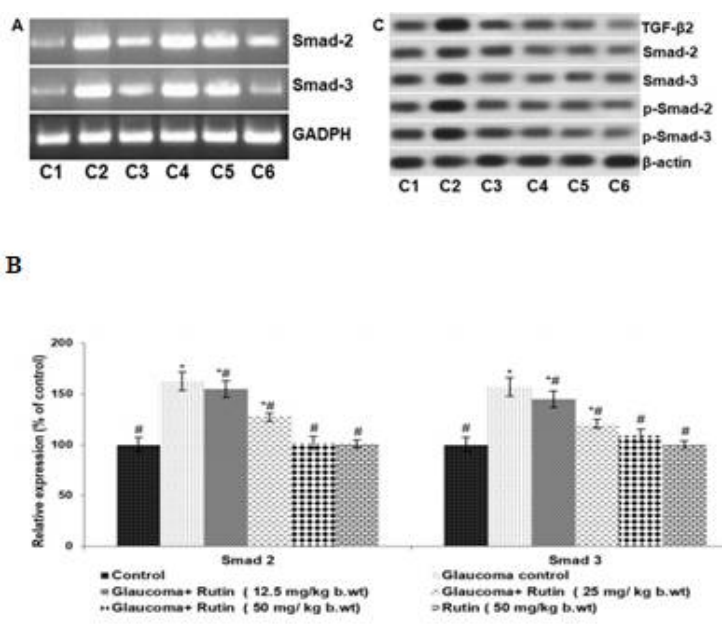

D

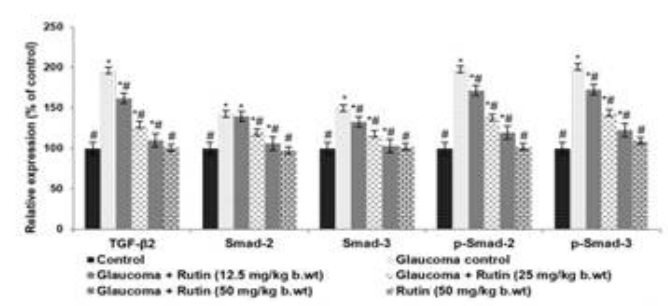

Figure 5: Effect of rutin on the expressions of Smad proteins. Rutin regulated the expressions of Smad-2 and Smad-3 both at mRNA (A \& B) and protein levels (C \& D). (A) SDS-PAGE showing Smad 2 and 3 mRNAs; (B) relative expressions of Smad2 and 3 mRNA, with control levels set at 100\%; (C) representative western blot results; (D) relative expression levels of proteins. Data are presented as mean $\pm \mathrm{SD}\left(\mathrm{n}=6,{ }^{*} p<0.05\right.$, compared to normal control; $\# p<0.05$, compared to glaucoma control. $\mathrm{Cl}=$ Control; C2 = glaucoma control; C3 = glaucoma + rutin $(12.5 \mathrm{mg} / \mathrm{kg})$; C4 = glaucoma+ rutin $(25 \mathrm{mg} / \mathrm{kg}) ; \mathrm{C} 5=$ glaucoma + rutin $(50 \mathrm{mg} / \mathrm{kg}) ; \mathrm{C} 6=$ rutin $(50 \mathrm{mg} / \mathrm{kg})$

\section{Rutin regulated Akt/PTEN signaling}

Significantly raised PTEN expressions were seen in rats injected with hypertonic saline alone, relative to normal control rats (Figure 6). The expression levels of phosphorylated forms of Akt and GSK-3 $\beta$ were markedly $(p<0.05)$ decreased in glaucoma control, when compared with normal rats, indicating down-regulation of the pathway. However, rutin administration resulted in a significant $(p<0.05)$ up-regulation of $p$-PTEN, indicating the activation of Akt signaling. In line with raised $p$-PTEN levels, up-regulated expression levels of phosphorylated forms of Akt and GSK-3 $\beta$ were also noticed.
A

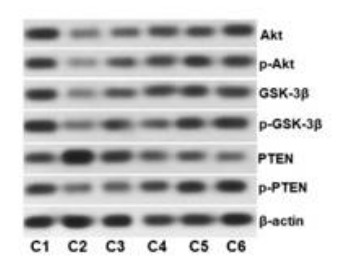

B

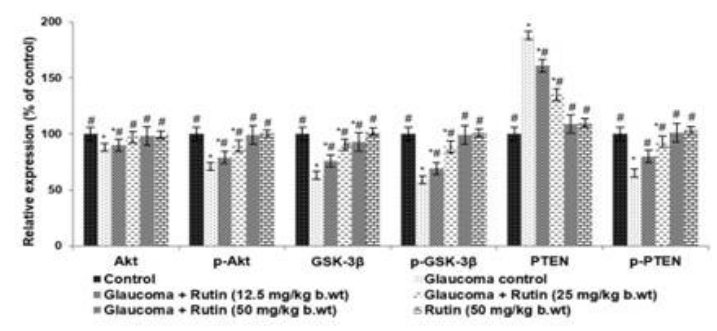

Figure 6: Effect of rutin on Akt signaling. (A) Representative immunoblot. (B) Relative expression levels, with control levels set at $100 \%$. Data are presented as mean $\pm \mathrm{SD}, \mathrm{n}=6$. ${ }^{*} p<0.05$, compared with normal control; $\# p<0.05$, compared with hypoxic control. $\mathrm{Cl}=$ Control; $\mathrm{C} 2$ = glaucoma control; $\mathrm{C} 3=$ glaucoma+ rutin $(12.5 \mathrm{mg} / \mathrm{kg}) ; \mathrm{C} 4$ = glaucoma+ rutin $(25 \mathrm{mg} / \mathrm{kg}) ; \mathrm{C} 5$ = glaucoma + rutin $(50 \mathrm{mg} / \mathrm{kg}) ; \mathrm{C} 6$ = rutin $(50 \mathrm{mg} / \mathrm{kg})$

\section{Rutin downregulated the expressions of ECM proteins}

A

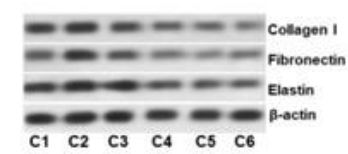

B

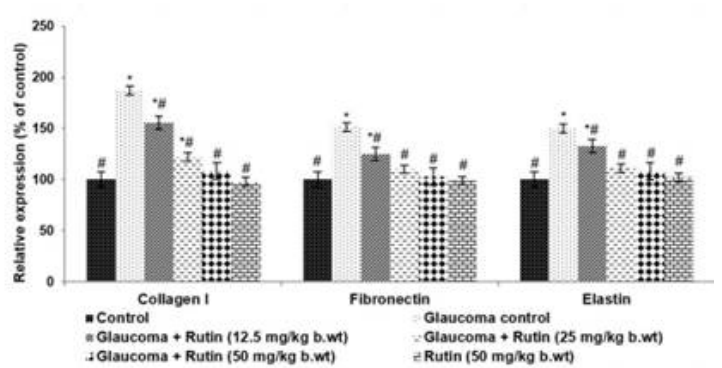

Figure 7: Effect of rutin on the expressions of ECM proteins in glaucoma. (A) Representative immunoblot. (B) Relative expression levels, with control levels set at $100 \%$. Data are presented as mean \pm SD $(n=6)$. ${ }^{*} p<0.05$, compared to normal control; \# $p<0.05$, compared to hypoxic control. $\mathrm{Cl}=$ Control; $\mathrm{C} 2=$ glaucoma control; C3 = glaucoma+ rutin $(12.5 \mathrm{mg} / \mathrm{kg})$; $\mathrm{C} 4$ = glaucoma + rutin $(25 \mathrm{mg} / \mathrm{kg}) ; \mathrm{C} 5=$ glaucoma + rutin $(50 \mathrm{mg} / \mathrm{kg}) ; \mathrm{C} 6=\operatorname{rutin}(50 \mathrm{mg} / \mathrm{kg})$

The expression of ECM proteins i.e. collagen I, fibronectin and elastin were significantly raised ( $p$ 
$<0.05)$ in rats following hypertonic saline injection, when compared with normal control (Figure 7). However, rutin administration resulted in down-regulation of collagen I expression. Furthermore, the levels of fibronectin and elastin were also significantly and dose-dependently ( $p$ $<0.05$ ) decreased, when compared to glaucoma control rats, with the $50 \mathrm{mg}$ dose exerting the most pronounced effects. The expression of collagen I decreased from 187.15 to $108.41 \%$ in rutin (50 $\mathrm{mg}$ )-treated rats.

\section{DISCUSSION}

Glaucoma is one of the most common ocular diseases characterized by progressive loss of vision, RGC death, cupping and degeneration of the optic nerve head [24]. Accumulating experimental data suggest several mechanisms associated with pathogenesis of glaucoma and RGC loss. Elevated IOP, aberrant inflammatory responses and altered apoptotic pathways are implicated in glaucoma [25]. Prevention of the loss of RGCs is crucial in glaucoma treatment. Current therapies in glaucoma treatment are chiefly targeted at reducing elevated IOP levels. However, there is an inevitable need to develop novel candidate drugs that can reduce RGC loss as well as inflammatory responses.

The present study investigated the protective effects of rutin in experimental glaucomatous rats. Rutin effectively prevented RGC cell death and improved viability of cells in in vivo model of glaucoma, and in vitro in hypoxia-induced RGC cells. Rutin regulated the expressions of proteins of the apoptotic pathway. The delicate balance between the pro-apoptotic proteins (Bad and $\mathrm{Bax}$ ) and anti-apoptotic proteins (Bcl-2 and Bcl$\mathrm{xL}$ ) is crucial in cell cycle regulation [26]. Rutinmediated up-regulation of expressions of $\mathrm{Bcl}-2$ and $\mathrm{Bcl}-\mathrm{xL}$ could have, in part, contributed to the increased RGC viability. Normally, Bcl-2 prevents the release of cytochrome $c$ from the mitochondria, while Bax induces cytochrome c release [27]. The increase in levels of cytochrome $\mathrm{c}$ in the extracellular space subsequently leads to the activation of caspase 3 and also the downstream proteins of the caspase cascade, which leads to apoptosis [28]. The significantly reduced expressions of $\mathrm{Bax}$, Bad and cleaved caspase- 3 observed in this study following rutin treatment indicate suppression of apoptosis. This suppression of pro-apototic proteins and cleaved caspase- 3 could have, in part, contributed to decreased apoptotic counts as observed in fluro gold staining. These findings suggest that rutin exerts protective effects against glaucoma.
Furthermore, the marked reduction in IOP following rutin treatment is a reflection of the efficacy of rutin in glaucoma treatment. Elevated IOP is well documented in progression of glaucoma and in RGC loss [25]. The reduction in IOP by rutin could have contributed to the prevention of RGC loss and improved viability. It has been reported that ECM plays a major role in regulating IOP, and that TGF- $\beta 2$ causes overproduction and deposition of ECM components fibronectin, collagen I and IV. Inhibitors of ECM proteases include plasminogen activator inhibitor-1 and tissue inhibitors of matrix metalloproteinases [29]. Alterations in ECM lead to impaired cell-cell signaling and increased resistance to $\mathrm{AH}$ outflow in $\mathrm{TM}$, leading to elevated IOP and cellular apoptosis [29]. The observed up-regulation in TGF- $\beta 2$ along with elevated levels of ECM components (collagen I, fibronectin and elastin) in the glaucomatous rats show that TGF- $\beta 2$-induced ECM accumulation led to elevated IOP as reported previously [30]. It has also been reported that TGF- $\beta 2$ increased $\mathrm{FN}$, collagen $\mathrm{I}$ and IV in glaucoma [31]. Furthermore, the enhanced expressions of phosphorylated forms of Smad-2 and Smad-3 observed in the present study suggest that activation of TGF- $\beta 2 /$ Smad- $2 / 3$ signaling caused increased expression of ECM components. It is known that activated TGF- $\beta 2-$ receptor complex phosphorylates and activates Smad-2 and Smad-3, leading to activation of the pathway [32]. The TGF- $\beta 2$-induced fibrosis operates through the canonical Smad pathway via Smad-2 and Smad-3 [33]. In the rutin-treated rats, the significantly down-regulated expressions of TGF$\beta 2, p-S m a d-2$ and $p-S m a d-3$ indicate downregulation of TGF- $\beta 2 / S m a d-2 / 3$ signaling. Reduced collagen I, fibronectin and elastin levels also indicate the inhibition of TGF- $\beta 2$-induced expressions of ECM components by rutin. The reduction in ECM components could have, in part, contributed to reduced IOP and RGC loss. These results reflect the potential efficacy of rutin in glaucoma therapy.

Furthermore, this study demonstrated markedly down-regulation of Akt signaling in glaucoma rats, as evidenced by enhanced PTEN levels and reduced Akt expression. The AKT signaling is a major pathway for the regulation of cell survival [34]. Thus, activation of the pathway plays a protective role in glaucoma.

Interestingly, rutin-mediated activation of the pathway, as evidenced by up-regulated expressions of $\mathrm{p}-\mathrm{AKt}$ and GSK-3 $\beta$ along with substantial down-regulation of PTEN, the major negative regulator of $\mathrm{AKT}$, may be responsible for the anti-apoptotic effects of rutin. The TGF- $\beta$ / 
Smad-2/3 signaling is regulated by PTEN [24]. Thus, the down-regulation of PTEN by rutin could have caused downregulated expressions of TGF$\beta /$ Smad-2/3. This may have contributed to the subsequent reduction in the expressions of ECM components. These observations suggest that rutin exerted substantial protective effects under glaucomatous conditions by significantly reducing IOP and decreasing RGC loss and deposition of ECM components, and by regulating major signaling pathways.

\section{CONCLUSION}

The results of the study reveal that rutin effectively reduces RGC loss, and decreases excess production of ECM components and IOP via regulation of TGF- $\beta / \mathrm{Smad} 2 / 3 / \mathrm{Akt} / \mathrm{PTEN}$ signaling pathway. These findings indicate the potential of rutin as a candidate drug for glaucoma therapy.

\section{DECLARATIONS}

\section{Conflict of interest}

No conflict of interest is associated with this work.

\section{Contribution of authors}

We declare that this work was done by the authors named in this article and all liabilities pertaining to claims relating to the content of this article will be borne by the authors. All authors have equally contributed to this study. Ying $\mathrm{Li}$, Liang Ying and Dabo Wang designed this study, collected and analysed the data, and also prepared the manuscript. Leilei Qin and Hanguang Dong contributed to the experimental work and statistical analysis.

\section{Open Access}

This is an Open Access article that uses a funding model which does not charge readers or their institutions for access and distributed under the terms of the Creative Commons Attribution License (http://creativecommons.org/licenses/by/ 4.0) and the Budapest Open Access Initiative (http://www.budapestopenaccessinitiative.org/rea d), which permit unrestricted use, distribution, and reproduction in any medium, provided the original work is properly credited.

\section{REFERENCES}

1. Calkins DJ. Critical pathogenic events underlying progression of neurodegeneration in glaucoma. Prog Retin Eye Res 2012; 31: 702-719.

2. Coleman AL, Miglior S. Risk factors for glaucoma onset and progression. Surv Ophthalmol 2008; 53: S3-10.

3. Rohen JW, Lutjen-Drecoll E, Flugel C, Meyer M, Grierson I. Ultrastructure of the trabecular meshwork in untreated cases of primary open-angle glaucoma (POAG). Exp Eye Res 1993; 56: 683-692.

4. Johnson M. 'What controls aqueous humour outflow resistance?' Exp Eye Res 2006; 82: 545-557.

5. Knepper PA, Goossens W, Hvizd M, Palmberg PF. Glycosaminoglycans of the human trabecular meshwork in primary opentangle glaucoma. Invest Ophthalmol Vis Sci 1996; 37: 1360-1367.

6. Saika S. TGF beta pathobiology in the eye. Lab Invest 2006; 86: 106-115.

7. Itoh $S$, Itoh F, Goumans MJ, Ten Dijke P. Signaling of transforming growth factor-beta family members through Smad proteins. Eur J Biochem 2000; 267: 6954-6967.

8. Fuchshofer R, Tamm ER. Modulation of extracellular matrix turnover in the trabecular meshwork. Exp Eye Res 2009; 88: 683-688.

9. Franke TF, Hornik $C P$, Segev L, Shostak GA, Sugimoto C. PIJK/Akt and apoptosis: size matters. Oncogene 2003; 22: 8983-8998.

10. Tsai RK, Chang CH, Sheu MM, Huang ZL. Anti-apoptotic effects of human granulocyte colony-stimulating factor (G-CSF) on retinal ganglion cells after optic nerve crush are PI3K/AKT-dependent. Exp Eye Res 2010; 90: 537545.

11. Mayer IA, Arteaga CL. The PI3K/AKT pathway as a target for cancer treatment. Annu Rev Med 2016; 67: 11-28.

12. Taylor A. Cataract: relationship between nutrition and oxidation. J Am Coll Nutr 1993; 12: 138-146.

13. Harborne JB. Nature, distribution and function of plant flavonoids. Prog Clin Biol Res 1986; 213: 15-24.

14. Azevedo MI, Pereira AF, Nogueira RB, Rolim FE, Brito $G A$, Wong DV, Lima-Júnior RC, de Albuquerque Ribeiro $R$, Vale $M L$. The antioxidant effects of the flavonoids rutin and quercetin inhibit oxaliplatin-induced chronic painful peripheral neuropathy. Mol Pain 2013; 9: 53.

15. Tongjaroenbuangam $W$, Ruksee $N$, Chantiratikul $P$, Pakdeenarong $N$, Kongbuntad $W$, Govitrapong $P$. Neuroprotective effects of quercetin, rutin and okra (Abelmoschus esculentus Linn.) in dexamethasonetreated mice. Neurochem Int 2011; 59: 677-685.

16. Kamalakkannan N, Prince PS. Anti-hyperglycaemic and antioxidant effect of rutin, a polyphenolic flavonoid, in streptozotocin- induced diabetic wistar rats. Basic Clin Pharmacol Toxicol 2006; 98: 97-103.

17. Araujo JR, Goncalves P, Martel F. Chemopreventive effect of dietary polyphenols in colorectal cancer cell lines. Nutr Res 2011; 31: 77-87.

18. Garber JC (Chair). Committee for the Update of the Guide for the Care and Use of Laboratory Animals. Guide for the Care and Use of Laboratory Animals, 
eighth ed. Washington DC, USA: National Academy of Sciences; 2011.

19. Husain S, Abdul Y, Singh S, Ahmad A, Husain M. Regulation of nitric oxide production by delta-opioid receptors during glaucomatous injury. PLoS One 2014; 9: e110397.

20. Moore CG, Epley D, Milne ST, Morrison JC. Long-term non-invasive measurement of intraocular pressure in the rat eye. Curr Eye Res 1995; 14: 711-717.

21. Wu CC, Bratton SB. Regulation of the intrinsic apoptosis pathway by reactive oxygen species. Antioxid. Redox Signal 2013; 19: 546-558.

22. Gao F, Li T, Hu J, Zhou X, Wu J, Wu Q. Comparative analysis of three purification protocols for retinal ganglion cells from rat. Mol Vis 2016; 22: 387-400.

23. Kim SJ, Ko JH, Yun JH, Kim JA, Kim TE, Lee HJ, Kim $S H$, Park KH, Oh JY. Stanniocalcin-1 protects retinal ganglion cells by inhibiting apoptosis and oxidative damage. PLoS One 2013; 8: e63749.

24. Thylefors $B$, Negrel $A D$. The global impact of glaucoma. Bull World Health Organ 1994; 72: 323-326.

25. Pease ME, McKinnon SJ, Quigley HA, KerriganBaumrind $L A$, Zack DJ. Obstructed axonal transport of $B D N F$ and its receptor TrkB in experimental glaucoma. Invest Ophthalmol Vis Sci 2000; 41: 764-774.

26. Zhao H, Yenari MA, Cheng D, Sapolsky RM, Steinberg GK. BCl-2 overexpression protects against neuron loss within the ischemic margin following experimental stroke and inhibits cytochrome $c$ translocation and caspase-3 activity. J Neurochem 2003; 85: 1026-1036.
27. Wang WY, Yang R, Hu SF, Wang H, Ma ZW, Lu Y. Nstearoyl--tyrosine ameliorates sevoflurane induced neuroapoptosis via MEK/ERK1/2MAPK signaling pathway in the developing brain. Neurosci Lett 2013; 541: 167-72.

28. Pradelli LA, Bénéteau M, Ricci JE. Mitochondrial control of caspase-dependent and -independent cell death. Cell Mol Life Sci 2010; 67: 1589-1597.

29. Hocevar BA, Howe PH. Analysis of TGF-beta-mediated synthesis of extracellular matrix components. Methods Mol Biol 2000; 142: 55-65.

30. Tian B, Geiger B, Epstein DL, Kaufman PL. Cytoskeletal involvement in the regulation of aqueous humor outflow. Invest Ophthalmol Vis Sci 2000; 41: 619-623.

31. Fuchshofer R, Birke M, Welge-Lussen U, Kook D, LutjenDrecoll $E$. Transforming growth factor-beta 2 modulated extracellular matrix component expression in cultured human optic nerve head astrocytes. Invest Ophthalmol Vis Sci 2005; 46: 568-578.

32. Montecchi-Palmer M, Bermudez JY, Webber HC, Patel GC, Clark AF, Mao W. TGFb2 induces the formation of cross-linked actin networks (CLANs) in human trabecular meshwork cells through the Smad and nonSmad dependent pathways. Invest Ophthalmol Vis Sci 2017; 58: 1288-1295.

33. von Bubnoff $A$, Cho KW. Intracellular BMP signaling regulation in vertebrates: pathway or network? Dev Biol 2001; 239: 1-14.

34. Song G, Ouyang G, Bao S. The activation of Akt/PKB signaling pathway and cell survival. J Cell Mol Med 2005; 9: 59-71. 